\title{
Mechanisms of Formation and Function of Eosinophil Lipid Bodies: Inducible Intracellular Sites Involved in Arachidonic Acid Metabolism
}

\author{
Patricia T Bozza*/+, Wengui Yu, Peter F Weller
}

\begin{abstract}
Harvard Thorndike Laboratory and Charles A. Dana Research Institute, Department of Medicine, Beth Israe Deaconess Medical Center and Harvard Medical School, Boston, MA, USA *Núcleo de Imunofarmacologia, Departamento de Fisiologia e Farmacodinâmica, Instituto Oswaldo Cruz, Av. Brasil 4365, 21045-900 Rio de Janeiro, RJ, Brasil
\end{abstract}

Lipid bodies, inducible lipid-rich cytoplasmic inclusions, are characteristically abundant in cells associated with inflammation, including eosinophils. Here we reviewed the formation and function of lipid bodies in human eosinophils. We now have evidence that the formation of lipid bodies is not attributable to adverse mechanisms, but is centrally mediated by specific signal transduction pathways. Arachidonic acid and other cis fatty acids by an NSAID-inhibitable process, diglycerides, and PAF by a 5lipoxygenase dependent pathway are potent stimulators of lipid body induction. Lipid body formation develops rapidly by processes that involve PKC, PLC, and de novo mRNA and protein synthesis. These structures clearly serve as repositoires of arachidonyl-phospholipids and are more than inert depots. Specific enzymes, including cytosolic phospholipase $A_{2}$, MAP kinases, lipoxygenases and cyclooxygenases, associate with lipid bodies. Lipid bodies appear to be dynamic, organelle-like structures involved in intracellular pathways of lipid mobilization and metabolism. Indeed, increases in lipid body numbers correlated with enhanced production of both lipoxygenase- and cyclooxygenase-derived eicosanoids. We hypothesize that lipid bodies are distinct inducible sites for generating eicosanoids as paracrine mediators with varied activities in inflammation. The capacity of lipid body formation to be specifically and rapidly induced in leukocytes enhances eicosanoid mediator formation, and conversely pharmacologic inhibition of lipid body induction represents a potential novel and specific target for anti-inflammatory therapy.

Key words: lipid bodies - eosinophils - eicosanoids - inflammation

Eicosanoids is the term used to describe a group of biologically active oxygenated fatty acids derived from the enzymatic metabolization of arachidonic acid. Eicosanoids function as paracrine mediators of inflammation as well as intracellular signals. Eicosanoids play major roles in inflammatory responses and have been implicated in the pathogenesis of many inflammatory diseases, including asthma, endotoxic shock, psoriasis, rheumatoid arthritis and inflammatory bowel disease (Henderson 1994, Serhan 1994). The synthesis of eicosanoids is catalyzed by lipoxygenases (LO) leading to the synthesis of leukotrienes (LT),

This work was supported by National Institutes of Health grants AI 20257. PT Bozza is a PEW Fellow in Biomedical Sciences, and is a recipient of postdoctoral fellowship from CNPq (Brazil).

${ }^{+}$Corresponding author. Fax: +55-21-590.9490. E-mail: pbozza@gene.dbbm.fiocruz.br

Received 3 September 1997

Accepted 30 September 1997
HETEs and lipoxins; and prostaglandin endoperoxide $\mathrm{H}$ synthases, also known as cyclooxygenase (COX) that metabolizes the arachidonic acid into prostaglandins (PG) and thromboxanes (Samuelsson et al. 1987, Smith et al. 1990, Sigal 1991). Although the enzymatic pathways for eicosanoid formation are well understood, the intracellular sites of action of these enzymes and the cellular sources of arachidonic acid remain less clear. The arachidonic acid is released from cellular arachidonyl-phospholipids, which may reside in various membranes, by the actions of phospholipases (Needleman et al. 1986, Lin et al. 1992). While translocation from cytosol to membranes may facilitate interactions of cytosolic enzymes with membrane-bound arachidonate, there is increasing evidence that specific compartmentalization of eicosanoid formation within cells may relate to the different autocrine and paracrine functions of eicosanoids (Serhan 1996, Smith et al. 1996). In addition to membranes, a novel putative site for paracrine eicosanoid production within inflammatory cells are lipid bodies. In this review 
we discuss the metabolic pathways for lipid body formation and the utilization of lipid body-derived arachidonate for eicosanoid synthesis.

\section{MECHANISMS OF LIPID BODY FORMATION IN HUMAN EOSINOPHILS}

Lipid bodies, although small in number, are normal constituent of leukocytes, including eosinophils. Interestingly, lipid bodies characteristically increase both in size and number in vivo in cells associated with inflammation; including leukocytes from joints of patients with inflammatory arthritis (Coimbra \& Lopes-Vaz 1971, Weinstein 1980, Schlesinger et al. 1982), the airways of patients with acute respiratory distress syndrome (Triggiani et al. 1995) and casein- or lipopoly-saccharide-elicited guinea pig peritoneal exudates (Robinson et al. 1982). In eosinophils, increased lipid body numbers have been observed in patients with hypereosinophilic syndrome (HES) (Solley et al. 1976, Weller et al. 1991a), in biopsies from Crohn's disease (Beil et al. 1995), and blood of antigen challenged asthmatic patients (Weller, unpublished observations).

Lipid bodies, identical to lipid bodies in leukocytes in vivo as evidenced both by light and electron microscopy, can also be rapidly (within 15-60 min) elicited in vitro after stimulation of cells with cis-unsaturated fatty acids, PAF or PKC activators (Weller et al. 1989, 1991b, Bozza et al. 1996a,b). Although incubation of leukocytes with exogenous phospholipids and fatty acids provides a source of lipids for incorporation into newly formed lipid bodies, mechanisms other than simple availability of lipid precursors seem to be involved in lipid body formation. First, specific unsaturated fatty acids, in a stereochemically restricted manner, can elicit $d e$ novo formation of lipid bodies in human leukocytes, whereas fully saturated fatty acids are not active (Weller et al. 1989, 1991b). Moreover, PAF but not its precursor and metabolite, lyso-PAF, that shares the lipid structure of PAF but has no receptor agonistic activity (for review see Braquet et al. 1987), have the capacity to induce lipid body formation (Bozza et al. 1996a, 1997). In addition, PAF stimulated eosinophil lipid body formation was dose-dependent $\left(10^{-8}-10^{-6} \mathrm{M}\right)$, with significant lipid body induction at nanomolar PAF concentrations, consistent with a receptor-dependent phenomenon (Bozza et al. 1997). In agreement, PAF-induced lipid body formation was dose-dependently inhibited by the PAF receptor antagonist WEB 2086. Moreover, $G$ protein coupled PAF receptor signaling is pertussis toxin sensitive (Murphy 1994), and pertussis toxin significantly inhibited PAF-induced lipid body formation in granulocytes (Bozza et al. 1996a, 1997). Interestingly, other leukocyte agonists, including
$\mathrm{LTB}_{4}, \mathrm{C} 5 \mathrm{a}$, FMLP and IL-8, that also signal through $\mathrm{G}$ protein coupled receptors failed to induce lipid body formation in neutrophils (Bozza et al. 1996a).

The downstream intracellular signaling pathways involved in lipid body formation were further evaluated. It has been demonstrated that rather than a toxic reaction of the cells, lipid body formation in leukocytes is a tightly controlled cellular response that involves the activation of different signaling pathways. A role for PKC mediation of lipid body formation has been suggested in studies using specific inhibitors (Weller et al. 1991b, Bozza et al.1996a). The PKC inhibitors staurosporine and H7 significantly inhibited the lipid body formation induced by PAF and cis fatty acids (Weller et al. 1991b, Bozza et al. 1996a). In addition, a similar degree of inhibition of lipid body formation was obtained by the treatment of leukocytes with two highly selective PKC inhibitors, chelerythrine, that interacts with the catalytic domain, and calphostin $\mathrm{C}$ that acts on the regulatory domain of PKC (Bozza et al., 1996a, 1997). Accordingly, it was previously demonstrated that direct PKC activators including 1-oleoyl-2-acetyl-glycerol and two active phorbol esters (phorbol myristate acetate and phorbol 12, 13 dibutyrate), but not an inactive phorbol, effectively induced lipid body formation in human neutrophils (Weller et al. 1991b). Pretreatment of cells with two specific phospholipase C (PLC) inhibitors, U-73122 (Yule \& Williams 1992) and D609, a phosphatidylcholine-PLC specific inhibitor (Shutze et al. 1992), drastically inhibited the stimulated induction of lipid bodies (Bozza et al. 1996a). Thus indicating that in addition to PKC activation, induction of leukocyte lipid bodies also requires the activation of PLC. In order to analyze whether new protein synthesis is required during the induction of lipid bodies in eosinophils, inhibitors of transcription (actinomycin D) and translation (cycloheximide) were evaluated. Pretreatment of eosinophils with either actinomycin D or cycloheximide significantly inhibited lipid body formation induced by PAF or cis fatty acids, thus indicating that the stimulated induction of lipid bodies depends on new protein synthesis and its likely that specific early response genes are activated during the process of lipid body formation (Bozza et al. 1996a,b, 1997). The formation of structurally distinct lipid bodies reflects mechanisms whereby proteins and lipids coalesce in a deliberate, highly regulated manner. Lipid body can result from mobilization and reorganization of endogenously-derived lipids as well as incorporating exogenous lipid. Thus, although lipid bodies are not conventional membrane-bound organelles, they appear to represent specialized intracellular whose induced formation is centrally related to activating mechanisms within the cells. 
LOCALIZATION OF EICOSANOID-FORMING ENZYMES TO HUMAN EOSINOPHIL LIPID BODIES

Lipid bodies are lipid-rich cytoplasmic inclusions that are candidates to play a major role in the formation of eicosanoid mediators during inflammation. Lipid bodies can be sites of esterified arachidonate localization in cells including neutrophils and eosinophils (Weller et al. 1989, 1991a). In human eosinophils lipid bodies have been shown to incorporate $\left[{ }^{3} \mathrm{H}\right]$-arachidonic acid into specific phospholipid classes by electron microscopic autoradiography and biochemical analysis of purified lipid bodies (Weller et al. 1991a). If lipid bodies are to have roles in eicosanoid mediator formation, then the arachidonic acid present in those lipid-rich structures must be liberated by phospholipases, and the free arachidonate must have access to eicosanoidforming enzymes. Accordingly, the co-compartmentalization of cytosolic phospholipase $\mathrm{A}_{2}\left(\mathrm{cPLA}_{2}\right)$ and mitogen-activated protein (MAP) kinases, the upstream enzymes involved in arachidonic acid liberation (Clark et al. 1990, Leslie 1991, Lin et al. 1993), within lipid bodies has been recently described (Yu et al. 1997 in press). Immunocytochemistry from whole cell and immunoblotting of proteins from isolated lipid bodies (free of cytosol and other organelles) established that cPLA $_{2}$ as well as the MAP kinases, ERK1, ERK2, p85 and p38, were localized at lipid bodies. In addition, isolated lipid body fractions contained cPLA 2 enzymatic activity and released arachidonic acid from $s n$-2-position of phosphatidylcholine (Yu et al. 1997).

The two major enzymes, 5-LO and COX, involved in the enzymatic conversion of arachidonic acid into eicosanoids within eosinophils were also shown to localize within lipid bodies. By using immunocytochemistry at the light level and ultrastructural postembedding immunogold, cyclooxygenase has been reported to localize at eosinophil lipid bodies, both in naturally formed lipid bodies in eosinophils from HES patients and in PAF-induced lipid bodies (Dvorak et al. 1992, 1994, Bozza et al 1997). Previous studies on the intracellular localization of 5-LO have shown that 5-LO localization is cell typespecific and also varies according to the activation state of the cell (Rouzer \& Kargman 1988, Reid et al. 1990, Woods et al. 1993, 1995, Brock et al. 1994). 5-LO was shown to localize within the nuclear environment (nuclear membrane and euchromatin) of alveolar macrophages and basophilic leukemia cells (Brock et al. 1994, Woods et al. 1995), whereas 5LO was found to be predominantly cytosolic in human neutrophils (Brock et al. 1994) and resting peritoneal macrophages (Peters-Golden \& McNish 1993). In addition to the nuclear environment, we have recently demonstrated the compartmentaliza- tion of the key enzyme for leukotriene production, 5-LO, within human eosinophil lipid bodies (Bozza et al. 1997). Interestingly, immuno-reactivity for 5LO was also detected in lipid bodies from enucleated human eosinophils (Bozza et al. 1997). Human eosinophils upon stimulation preferentially produce $\mathrm{LTC}_{4}$ as their 5-LO product (Weller et al. 1983). $\mathrm{LTC}_{4}$-synthase is the terminal LT-forming enzyme and is present selectively in eosinophils, basophils and mast cells (MacGlashan et al. 1982, 1986, Weller et al., 1983). Similarly to that observed for 5-LO, $\mathrm{LTC}_{4}$-synthase was shown to co-localize within eosinophil lipid bodies (Bozza et al. 1997). Together our findings support a role for lipid bodies to function as specific sites for eicosanoid formation. The compartmentalization of arachidonate substrate (Weller et al. 1989, 1991), cPLA 2 (Yu et al. 1997), and eicosanoid-forming enzymes (Dvorak et al. 1992, 1994, Bozza et al. 1997) provides in one locale an efficient mean to regulate arachidonate release and directly couple it with the enzymes to form eicosanoids.

\section{INVOLVEMENT OF LIPID BODIES IN ENHANCED GENERATION OF EICOSANOIDS BY EOSINOPHILS}

Because eosinophil lipid bodies are sites of intracellular localization of eicosanoid-forming enzymes (Dvorak et al. 1994, Bozza et al. 1997) and also stores of the eicosanoid precursor arachidonic acid (Weller et al. 1989, 1991a), we analyzed if increases in lipid body numbers in eosinophils would correlate with increased $\mathrm{LTC}_{4}$ and $\mathrm{PGE}_{2}$ production by human eosinophils. Indeed, stimuli known to prime leukocytes to induce eicosanoid generation, including PKC activators, arachidonate and PAF (Bauldry et al. 1988, 1991, Stewart et al. 1990, Bozza et al. 1996a, b), are also active in stimulating lipid body formation (Weller et al. 1991b, Bozza et al. 1996a, b, 1997). Accordingly, we observed a significant correlation between PAF-induced lipid body formation and enhanced generation of both LO- and COX-derived eicosanoids in human neutrophils and eosinophils (Bozza et al. 1996a, 1997). A similar enhancement in eicosanoid production by eosinophils was also observed after lipid body induction by $c i s$-fatty acids (Bozza et al. 1996b). Analogously, agents that inhibited lipid body formation also resulted in inhibited priming for eicosanoid production. Pretreatment of granulocytes with the protein synthesis inhibitors actinomycin D or cycloheximide inhibited not only PAF-induced lipid body formation, but also priming for $\mathrm{LTC}_{4}$ and $\mathrm{PGE}_{2}$ release by eosinophils, under conditions where they failed to inhibited calcium ionophore-induced $\mathrm{LTC}_{4}$ and $\mathrm{PGE}_{2}$ in cells not prestimulated with PAF (Bozza et al. 1996a, 1997). In order to evaluate the role of cytoplasmic lipid bodies in enhanced eicosanoid 
formation independently of the nuclear-pool of eicosanoid-forming enzymes and lipids, eosinophil enucleated cytoplasts were studied. As observed with intact eosinophils, PAF-induced a dose-dependent increase in the number of lipid bodies in eosinophil cytoplasts. Likewise, PAF-induced lipid body formation in nuclei-free cytoplast strongly correlated with increased $\mathrm{LTC}_{4}$ and $\mathrm{PGE}_{2}$ production following submaximal stimulation with A23187 (Bozza et al. 1997).

Collectively these findings indicate that lipid bodies are cytoplasmic, nuclei independent, sites for eicosanoid-forming enzyme localization and eicosanoid production. Taken together with the evidences indicating the nucleus environment as important pools for eicosanoid metabolism (Serhan 1996, Smith et al. 1996), our findings raise intriguing possibilities that different sites for eicosanoid production might exist in a cell leading to the production of eicosanoids for autocrine release within the nuclei acting as regulators of transcription or external release as paracrine inflammatory mediators.

\section{INHIBITION OF LIPID BODY INDUCTION}

In light of the putative role that lipid bodies may play in the development of inflammation, the effect of anti-inflammatory drugs on lipid body formation was studied. Lipid body induction by PAF required 5-LO activity, and was inhibited by the FLAP antagonist, MK 886, and the 5-LO inhibitor, zileuton, but not by COX inhibitors. Corroborating the dependency of PAF-induced lipid body formation on 5-LO, PAF failed to increase lipid body numbers in cells obtained from 5-LO knockout mice. Likewise, the capacity of PAF to elicit lipid body formation in vivo was shown to be 5-LO dependent in studies with an acute model of inflammation in mice. The intrathoracic injection of PAF significantly increased the number of lipid bodies in pleural resident macrophages and in the neutrophils that migrated to the pleural cavity from wild-type mice, but failed to stimulate macrophages or neutrophils from 5-LO knockout mice. These findings indicate the requisite role for 5-LO activity in the in vitro and in vivo induction of leukocyte lipid bodies by PAF (Bozza et al. 1996a).

In contrast, lipid body formation induced by cisunsaturated fatty acids is independent of 5-LO activation, but is inhibited by non-steroidal anti-inflammatory drugs including aspirin, indomethacin and sodium salicylate (Bozza et al. 1996b). Interestingly, the non-cyclooxygenase inhibitor, sodium salicylate, was as potent as aspirin in inhibiting the lipid body formation elicited by cis-fatty acids, thus suggesting that the inhibitory effect of aspirin in lipid body formation is independent of COX inhibition. In ad- dition, cis-fatty acids-induced lipid body formation in cells from COX-1 and COX-2 deficient mice was not impaired; and NSAIDs, including aspirin, sodium salicylate, indomethacin and NS-398, inhibited arachidonic acid-induced lipid body formation equally in macrophages from wild-type, and COX-1 or COX-2 deficient mice (Bozza et al. 1996b). Other evidence also suggests $\mathrm{COX}-2$ does not participate in lipid body formation. COX-2 induction takes 2 48 h (Lee et al. 1992, Reddy \& Herschman 1994, Smith et al. 1994), whereas lipid body formation occurs within $1 \mathrm{~h}$ (Weller et al. 1991b, Bozza et al. 1996a, b, 1997). Furthermore, dexamethasone, a potent inhibitor of COX-2 expression (Kujubu \& Herschman 1992), did not block lipid body formation (Bozza et al. unpublished observations). Thus, COX-2 is unlikely to have a role in the induction of lipid bodies, and since this induction can still occur in COX-1 deficient macrophages neither COX is essential in this process.

In view of the ability of aspirin to inhibit lipid body formation both in vivo and in vitro (Reginato et al. 1985, Bozza et al. 1996b), we evaluated whether the inhibitory effect of aspirin on lipid body formation would have an effect on cis-fatty acidinduced priming for enhanced production of both $\mathrm{COX}$ and 5-LO metabolites. Pretreatment of leukocytes with aspirin significantly inhibited $\mathrm{PGE}_{2}$ production by neutrophils and eosinophils in either vehicle- or cis-fatty acid-stimulated leukocytes, but such an effect might be based on the known ability of aspirin to inhibit COX (Bozza et al. 1996b). It has been well documented that aspirin is devoid of any direct inhibitory effects upon lipoxygenases in leukocytes and platelets (Cerletti et al. 1983, Punnonen \& Uotila 1984, Cerletti 1985). However, aspirin and aspirin-like drugs were shown to indirectly regulate lipoxygenase activity in different systems (Siegel et al. 1980, Paajanen et al. 1982, Villanueva et al. 1993). In our studies, aspirin significantly inhibited cis-fatty acid-induced priming for enhanced $\mathrm{LTB}_{4}$ production by neutrophils and $\mathrm{LTC}_{4}$ production by eosinophils. Moreover, the effect of aspirin on inhibiting priming for enhanced eicosanoid production was correlated with its ability to inhibit $c i s$-fatty acid-induced lipid body formation (Bozza et al. 1996b). Those results suggest that the capacity of aspirin to inhibit the induction of lipid bodies may enable aspirin to inhibit formation of both cyclooxygenase and lipoxygenase pathway derived eicosanoids and help to elucidate its range of anti-inflammatory activities.

\section{CONCLUDING REMARKS}

In the present study we review the evidence for a role of lipid bodies as specific inducible sites of eicosanoid mediator formation. Of special interest 
for human diseases, those structures are naturally occurring in vivo in a variety of inflammatory pathological conditions, many of which are also known to have enhanced generation of arachidonic acid metabolites, such as leukotrienes and prostaglandins.

In conclusion, we have been identifying cytoplasmic inclusions, termed lipid bodies, as having previously unrecognized roles in the paracrine formation of eicosanoid mediators of inflammation. Lipid bodies are specialized intracellular domains for eicosanoid-forming enzyme localization, whose formation is specifically inducible, dependent upon transcriptional activation of early response genes and highly regulated by intracellular signaling pathways. Moreover, the capacity of inhibitors of lipid body formation to block eicosanoid generation identifies a novel target for anti-inflammatory drug action.

\section{REFERENCES}

Bauldry SA, Wykle RL, Bass DA 1988. Phospholipase $\mathrm{A}_{2}$ activation in human neutrophils. Differential actions of diacylglycerols and alkylacylglycerols in priming cells for stimulation by $\mathrm{N}$-formyl-met-leuphe. J Biol Chem 263: 16787-16795.

Bauldry SA, Wykle RL, Bass DA 1991. Differential actions of diacyl- and alkylacylglycerols in priming phospholipase $A_{2}, 5$-lipoxygenase and acetyltransferase activation in human neutrophils. Bioch Biophys Acta 1991: 178-184.

Beil WJ, Weller PF, Peppercorn MA, Galli SJ, Dvorak AM 1995. Ultrastructural immunogold localization of subcellular sites of TNF- $\alpha$ in colonic Crohn's disease. J Leuk Biol 58: 284-298.

Bozza PT, Payne JL, Goulet JL, Weller PF 1996a. Mechanisms of PAF-induced lipid body formation: a requisite role for 5-lipoxygenase in the compartmentalization of neutrophil lipids. J Exp Med 183: 1515-1525.

Bozza PT, Payne JL, Morham SG, Langenbach R, Smithies O, Weller PF 1996b. Leukocyte lipid body formation and eicosanoid generation: cyclooxygenaseindependent inhibition by aspirin. Proc Natl Acad Sci USA 93: 11091-11096.

Bozza PT, Yu W, Penrose JF, Morgan ES, Dvorak AM, Weller PF 1997. Eosinophil lipid bodies: specific, inducible intracellular sites for enhanced eicosanoid formation. J Exp Med 186: 909-920.

Braquet P, Touqui L, Shen T, Vargaftig BB 1987. Perspectives in platelet-activating factor research. Pharmacol Rev 39: 2-97.

Brock TG, Paine R Jr, Peters-Golden M 1994. Localization of 5-lipoxygenase to the nucleus of unstimulated rat basophilic leukemia cells. J Biol Chem 269: 22059-22066.

Cerletti C 1985. Interaction of non-steroidal anti-inflammatory drugs on platelet cyclo-oxygenase and lipoxygenase activity. Int J Tissue React 7: 309-312.

Cerletti C, Livio M, Doni MG, De Gaetano G 1983. Salicylate fails to prevent the inhibitory effect of $5,8,11,14$ - eicosatetraynoic acid on human platelet cyclo-oxygenase and lipoxygenase activities. Biochim Biophys Acta 759: 125-127.
Clark JD, Milona N, Knopf JL 1990. Purification of a 110-kilodalton cytosolic phospholipase $\mathrm{A}_{2}$ from the human monocytic cell line U937. Proc Natl Acad Sci USA 87: 7708-7712.

Coimbra A, Lopes-Vaz A 1971. The presence of lipid droplets and the absence of stable sudanophilia in osmium-fixed human leukocytes. J Histochem Cytochem 19: 551-557.

Dvorak AM, Morgan E, Schleimer RP, Ryeom SW, Lichtenstein LM, Weller PF 1992. Ultrastructural immunogold localization of prostaglandin endoperoxide synthase (cyclooxygenase) to nonmembranebound cytoplasmic lipid bodies in human lung mast cells, alveolar macrophages, type-II pneumocytes and neutrophils. J Histochem Cytochem 40: 759-769.

Dvorak AM, Morgan E, Tzizik DM, Weller PF 1994. Prostaglandin endoperoxide synthase (cyclooxygenase): ultrastructural localization to nonmembranebound cytoplasmic lipid bodies in human eosinophils and murine 3T3 fibroblasts. Int Arch Allergy Immunol 105: 245-250.

Henderson WRJr 1994. The role of leukotrienes in inflammation. Ann Intern Med 121: 684-697.

Kujubu DA, Herschman HR 1992. Dexamethasone inhibits mitogen induction of the TIS10 prostaglandin synthase/cyclooxygenase gene. J Biol Chem 267: 7991-7994.

Lee SH, Soyoola E, Chanmugam P, Hart S, Sun W, Zhong H, Liou S, Simmons D, Hwang D 1992. Selective expression of mitogen-inducible cyclooxygenase in macrophages stimulated with lipopolysaccharide. J Biol Chem 267: 25934-25938.

Leslie CC 1991. Kinetic properties of a high molecular mass arachidonyl-hydrolyzing phospholipase $\mathrm{A}_{2}$ that exhibits lysophospholipase activity. J Biol Chem 266: 11366-11371.

Lin LL, Lin AY, Knopf JL 1992. Cytosolic phospholipase $A_{2}$ is coupled to hormonally regulated release of arachidonic acid. Proc Natl Acad Sci USA 89: 6147-6151.

Lin L-L, Wartmann M, Lin AY, Knopf JL, Seth A, Davis RJ 1993. $\mathrm{CPLA}_{2}$ is phosphorylated and acivated by MAP kinase. Cell 72: 269-278.

MacGlashan DJr, Peters SP, Warner J, Lichtenstein LM 1986. Characteristics of human basophil sulphidopeptide leukotriene release: releasability defined as the ability of the basophil to respond to dimer cross-links. J Immunol 136: 2231-2236.

MacGlashan DJr, Schleimer RP, Peters SP, Schulman ES, Adams GKIII, Newball NH, Lichtenstein LM 1982. Generation of leukotrienes by purified human lung mast cells. J Clin Invest 70: 747-751.

Murphy PM 1994. The molecular biology of leukocyte chemoattractant receptors. Annu Rev Immunol 12: 593-633.

Needleman P, Turk J, Jakschik BA, Morrison AR, Lefkowith JB 1986. Arachidonic acid metabolism. Ann Rev Biochem 55: 69-102.

Paajanen H, Mannisto J, Uotila P 1982. Aspirin inhibits arachidonic acid metabolism via lipoxygenase and cyclo-oxygenase in hamster isolated lungs. Prostaglandins 23: 731-741.

Peters-Golden M, McNish RW 1993. Redistribution of 
5-lipoxygenase and cytosolic phospholipase $\mathrm{A}_{2}$ to the nuclear fraction upon macrophage activation. Biochem Biophys Res Commun 196: 147-153.

Punnonen K, Uotila P 1984. The effect of aspirin on the metabolism of exogenous arachidonic acid in human polymorphonuclear leukocytes. Prostaglandins Leukot Med 15: 177-185.

Reddy ST, Herschman HR 1994. Ligand-induced prostaglandin synthesis requires expression of the TIS10/ PGS-2 prostaglandin synthase gene in murine fibroblasts and macrophages. J Biol Chem 269: 1547315480 .

Reginato AJ, Schumacher HR, Allan DA, Rabinowitz JL 1985. Acute monoarthritis associated with lipid liquid crystals. Ann Rheum Dis 44: 537-543.

Reid GK, Kargman S, Vickers PJ, Mancini JA, Leveille C, Ethier D, Miller DK, Gillard JW, Dixon RA, Evans JF 1990. Correlation between expression of 5-lipoxygenase-activating protein, 5-lipoxygenase, and cellular leukotriene synthesis. J Biol Chem 265: 19818-19823.

Robinson JM, Karnovsky ML, Karnovsky MJ 1982. Glycogen accumulation in polymorphonuclear leukocytes, and other intracellular alterations that occur during inflammation. J Cell Biol 95: 933-942.

Rouzer CA, Kargman S 1988. Translocation of 5lipoxygenase to the membrane in human leukocytes challenged with ionophore A23187. J Biol Chem 263: 10980-10988.

Samuelsson B, Dahlen SE, Lindgren JA, Rouzer CA, Serhan CN 1987. Leukotrienes and lipoxins: structures, biosynthesis, and biological effects. Science 237: 1171-1176.

Schlesinger PA, Stillman MT, Peterson L 1982. Polyarthritis with birefringent lipid within synovial fluid macrophages: case report and ultrastructural study. Arthritis Rheum 25: 1365-1368.

Serhan CN 1994. Eicosanoids in leukocyte function. Cur Op Hematol 1: 69-77.

Serhan CN 1996. Signalling the fat controller. Nature 384: 23-24.

Shutze S, Potthoff K, Machleidt T, Berkovic D, Wiegmann K, Kronke M 1992. TNF activates NF$\mathrm{kB}$ by phosphatidylcholine-specific phospholipaseC-induced "acidic" sphingomyelin breakdown. Cell 71: 765-776.

Siegel MI, McConnell RT, Porter NA, Selph JL, Truax JF, Vinegar R, Cuatrecasas P 1980. Aspirin-like drugs inhibit arachidonic acid metabolism via lipoxygenase and cyclo-oxygenase in rat neutrophils from carrageenan pleural exudates. Biochem Biophys Res Commun 92: 688-695.

Sigal E 1991. The molecular biology of mammalian arachidonic acid metabolism. Am J Physiol 260: L13L28.

Smith WL, DeWitt DL, Kraemer SA, Andrews MJ, Hla T, Maciag T, Shimokawa, T 1990. Structure-function relationships in sheep, mouse, and human prostaglandin endoperoxide $\mathrm{G} / \mathrm{H}$ synthases. In B Samuelsson et al.(eds.). Advances in Prostaglandin, Thromboxane and Leukotriene Research. Raven Press, New York.

Smith W L, Garavito RM, DeWitt DL 1996. Prostag- landin endoperoxide $\mathrm{H}$ synthases (cyclooxygenases)1 and -2. J Biol Chem 271: 33157-33160.

Smith WL, Meade EA, DeWitt DL 1994. Pharmacology of prostaglandin endoperoxide synthase isozymes-1 and - 2. Ann N Y Acad Sci 714: 136-142.

Solley GO, Maldonado JE, Gleich GJ, Giulani ER, Hoagland HC, Pierre RV, Brown ALJr 1976. Endomyocardiophaty with eosinophilia. Mayo Clin Proc 51: 697-708.

Stewart AG, Dubbin PN, Harris T, Dusting GJ 1990. Platelet-activating factor may act as a second messenger in the release of icosanoids and superoxide anions from leukocytes and endothelial cells. Proc Natl Acad Sci USA 87: 3215-3219.

Triggiani M, Oriente A, Seeds MC, Bass DA, Marone G, Chilton FH 1995. Migration of human inflammatory cells into the lung results in the remodeling of arachidonic acid into a triglyceride pool. $J$ Exp Med 182: 1181-1190.

Villanueva M, Heckenberger R, Strobach H, Palmer M, Schror K 1993. Equipotent inhibition by R (-)-, S $(+)$ - and racemic ibuprofen of human polymorphonuclear cell function in vitro. Br J Clin Pharmac 35: 235-242.

Weinstein J 1980. Synovial fluid leukocytosis associated with intracellular lipid inclusions. Arch Intern Med 140: 560-561.

Weller PF, Ackerman SJ, Nicholson-Weller A, Dvorak AM 1989. Cytoplasmic lipid bodies of human neutrophilic leukocytes. Am J Pathol 135: 947-959.

Weller PF, Lee CW, Foster DW, Corey EJ, Austen KF, Lewis RA 1983. Generation and metabolism of 5lipoxygenase pathway leukotrienes by human eosinophils: predominant production of leukotriene $\mathrm{C}_{4}$. Proc Natl Acad Sci USA 80: 7626-7630.

Weller PF, Monahan-Earley RA, Dvorak HF, Dvorak AM 1991a. Cytoplasmic lipid bodies of human eosinophils: subcellular isolation and analysis of arachidonate incorporation. Am J Pathol 138: 141148.

Weller PF, Ryeom SW, Picard ST, Ackerman SJ, Dvorak AM 1991b. Cytoplasmic lipid bodies of neutrophils: Formation induced by $c i s$-unsaturated fatty acids and mediated by protein kinase C. J Cell Biol 113: 137 146.

Woods JW, Coffey MJ, Brock TG, Singer II, PetersGolden M 1995. 5-Lipoxygenase is located in the euchromatin of the nucleus in resting human alveolar macrophages and translocates to the nuclear envelope upon cell activation. J Clin Invest 95: 2035-2046.

Woods JW, Evans JF, Ethier D, Scott S, Vickers P J, Hearn L, Heibein JA, Charleson S, Singer II 1993. 5-lipoxygenase and 5-lipoxygenase-activating protein are localized in the nuclear envelope of activated human leukocytes. J Exp Med 178: 1935-1946.

Yu W, Bozza PT, Tzizik DM, Payne JL, Dvorak AM, Weller PF 1997. Co-compartmentalization of MAP kinases and cytosolic phospholipase $\mathrm{A}_{2}$ at cytoplasmic lipid bodies. Am J Pathol (in press).

Yule DI, Williams JA 1992. U73122 inhibits $\mathrm{Ca}^{2+}$ oscillations in response to cholecystokinin and carbachol but not to JMV-180 in rat pancreatic acinar cells. J Biol Chem 267: 13830-13835. 